\title{
A case report on congenital rubella syndrome
}

\author{
M. Kanagadurga* \\ Department of Obstetrics and Gynecology, Sri Gokulam College of Nursing, Tamil Nadu, India
}

Received: 25 July 2020

Revised: 06 October 2020

Accepted: 29 December 2020

\section{*Correspondence:}

M. Kanagadurga,

E-mail: durgaraj86@yahoo.co.in

Copyright: (c) the author(s), publisher and licensee Medip Academy. This is an open-access article distributed under the terms of the Creative Commons Attribution Non-Commercial License, which permits unrestricted non-commercial use, distribution, and reproduction in any medium, provided the original work is properly cited.

\begin{abstract}
Congenital rubella syndrome (CRS) is a rare illness in infants that result from maternal infection with rubella virus during pregnancy. The case reported is a primigravida at 37.3 weeks of gestation with the complaints of headache, decreased urine output, bilateral pedal edema, puffiness of face and mild hydromnios suggesting pregnancy-induced hypertension $(\mathrm{PIH})$. The previous data showed that the fetus had bone anomalies. Controversially the mother had rubella immune before 12 weeks of pregnancy but the report of nuchal translucency (NT) scan taken during 12 weeks of pregnancy was normal. On history mother denied any evidence of rubella infection during or recently before pregnancy which shows it was asymptomatic. She was treated for PIH. By lower segment caesarean section (LSCS), she delivered an alive boy baby who was acrocyanotic and had deformity in all long bones and enlarged liver. Placenta was found to be abnormal. The baby was under observation and the investigation confirmed CRS. Baby had bradycardia and was intubated on following days and found baby's vocal cord shape was abnormal. Baby had seizures and could not tolerate weaning from ventilator. Before further investigations, the baby was discharged against medical advice. Though very rare, CRS was found to have many consequences to the fetus. Hence it is significant to rule out rubella infection for mother during or recently before pregnancy as a part of routine antenatal checkup as many of them are asymptomatic. All women should be insisted about getting vaccination for rubella minimum 28 days before planning for conception and should be abandoned for those who were already pregnant.
\end{abstract}

Keywords: CRS, Pregnancy, Anomalies, Consequences, Routine investigations, Vaccination

\section{INTRODUCTION}

Congenital rubella syndrome (CRS) is a rare illness in infants that result from maternal infection with rubella virus during pregnancy. When rubella infection occurs during early pregnancy, serious consequences can result. ${ }^{1}$ Nearly one half of individuals infected with the virus are asymptomatic.

\section{CASE REPORT}

The case reported here is a primigravida at 37.3 weeks of gestation who got her initial treatment in a foreign country followed by treatment in a private hospital at Tamil Nadu, India. She was found to have pregnancy induced hypertension (PIH) and hence she was referred to the hospital where her condition was taken for the case report.

The woman had the complaints of headache since 2 days and decreased urine output since 10 days. On examination, she had bilateral pedal edema and puffiness of face. On palpation P/A uterus was about 36 weeks and mild hydromnios was present. On investigation, patients' blood value showed increased white blood cells (WBC) (14500 cells/cu.mm), increased neutrophils (84\%), decreased lymphocytes $(12 \%)$, decreased serum albumin $(1.6 \mathrm{~g} / \mathrm{dl})$ and increased serum alkaline phosphatase (170 U/l).

The data from the previous record showed that the fetus has indrawn mandible and shortening of long bones from 
the ultrasonography (USG) taken around 30 weeks of gestation. The controversial finding is that in routine investigations done in early pregnancy showed that mother had rubella immune in the month of July 2019. But the report of nuchal translucency (NT) scan taken during 12 weeks of pregnancy in September 2019 was normal (1.5 $\mathrm{mm})$. On history mother denied any evidence of rubella infection during pregnancy or recently before pregnancy which shows that she might be asymptomatic.

The woman was treated with injection magnesium sulphate, tablet labetalol and tablet calcigard for PIH and planned for induction at night on the day of admission. But she started having labour pains before induction and she was found to have early and late decelerations and baby position was in left occiput transverse (LOT). As there was no significant progress in labour, she was posted for LSCS.

By LSCS, she delivered an alive boy baby of birth weight $3 \mathrm{~kg}$ with Apgar 7/10 in 1 minute and 8/10 in 5 minutes. Baby cried after suctioning and stimulation. Baby was acrocyanotic and had deformity in all long bones (shortening of long bones) and enlarged liver. Baby passed urine and meconium immediately after birth and had pulse rate $(\mathrm{PR})$ - 120/minute and respiratory rate (RR) $48 /$ minute. Followed by baby delivery, placenta was removed and it was found to be a huge placenta weighing 860 gm with lengthy umbilical cord. Investigations for the baby were sent to rule out CRS.

The baby was kept on observation in neonatal intensive care unit (NICU) and the investigation report confirmed CRS. The second day of birth, baby went for bradycardia and the baby was intubated as the condition was not stable. On intubation, it was found that baby's vocal cord shape was abnormal. On the same day of LSCS, mother was investigated for hemoglobin $(\mathrm{Hb})$, platelet, prothrombin time (PT) and USG pelvis. The report was found to be normal. The condition of the mother was good on following days and carried out with routine management. On the following day, baby had seizures and could not tolerate weaning from ventilator. When about to investigate for the presence of other complications, the baby was discharged against medical advice.

\section{Disease condition}

The name rubella is derived from a Latin word term meaning "little red". Rubella is generally a benign communicable exanthematous disease. It is caused by rubella virus, which is a member of the rubivirus genus of the family togaviridae. ${ }^{2}$ Nearly one half of individuals infected with this virus are asymptomatic.

CRS can occur in a developing fetus of a pregnant woman who has contracted rubella usually in the first trimester. If infection occurs 0-28 days before conception, the infant has a $43 \%$ risk of being affected. If the infection occurs 0 12 weeks after conception, the risk increases to $81 \%$. If the infection occurs 13-26 weeks after conception, the risk is
$54 \%$ of the infant being affected by the disease. Infants are not generally affected if rubella is contracted during the third trimester or 26-40 weeks after conception. Problems rarely occur when rubella is contracted by the mother after 20 weeks of gestation and continues to disseminate the virus after birth. ${ }^{3}$

The classic triad for CRS is: sensorineural deafness (58\%), eye abnormalities - especially retinopathy, cataract, glaucoma and microphthalmia (43\%), and congenital heart disease - especially pulmonary artery stenosis and patent ductus arteriosus $(50 \%)$.

Other manifestations include: spleen, liver or bone marrow problems; intellectual disability; microcephaly; low birth weight; thrombocytopenia purpura; extramedullary hematopoiesis; enlarged liver; small jaw size; and skin lesions.

They should also be watched for: developmental delay, autism, schizophrenia, growth retardation, learning disabilities, and diabetes mellitus.

Common congenital defects of CRS include cataracts, congenital heart disease, hearing impairment and developmental delay. Infants with CRS often present with more than 1 sign or symptoms consistent with congenital rubella infection. However infants may present with a single defect with hearing impairment being the most common single defect. ${ }^{3,4}$

An infant with at least one of the symptoms clinically consistent with CRS listed above was confirmed and laboratory evidence of congenital rubella infection was demonstrated by: isolation of rubella virus, detection of rubella-specific immunoglobulin $\mathrm{M}(\operatorname{IgM})$ antibody, infant rubella antibody level that persists at a higher level and for a longer period of time than expected from passive transfer of maternal antibody (i.e. rubella titer that does not drop at the expected rate of a 2-fold decline per month), a specimen that is polymerase chain reaction (PCR)-positive for rubella virus. ${ }^{3}$

\section{Long-term outlook}

The long-term outlook for a child born with CRS depends on the severity of the birth defects. If the baby has problems with heart, they can often be corrected, while nervous system damage can often be irreversible. Because there is no cure for CRS, it's important to prevent it. If your baby is born with CRS, specific symptoms of the disease can be treated accordingly. ${ }^{4}$

\section{Treatment}

Treatment was done by counseling and possibly immunoglobulin for the mother.

No specific therapy is available for maternal or congenital rubella infection. Women exposed to rubella early in 
pregnancy should be informed of the potential risks to the fetus.

Some experts recommend giving nonspecific immune globulin $(0.55 \mathrm{ml} / \mathrm{kg} \mathrm{IM})$ for exposure early in pregnancy, but this treatment does not prevent infection, and the use of immune globulin should be considered only in women who decline pregnancy termination. ${ }^{5}$

\section{Prevention}

Vaccinating the females who plan on pregnancy is highly recommended at least 28 days prior to conception. If already pregnant, vaccination is strictly prohibited. Other preventive actions include the screening and vaccinations of high risk personnel such as medical and child care professionals. $^{6}$

\section{Complications}

The major complication of rubella is its teratogenic effects when pregnant women contract the disease, especially in the early weeks of gestation. The virus can be transmitted to the fetus through the placenta and is capable of causing serious congenital defects, abortions and stillbirths. ${ }^{2}$

\section{DISCUSSION}

Presented here is a case of CRS in which the mother had no symptoms of rubella infection in pregnancy but routine investigation showed the presence of rubella immune and the fetus was affected by the infection and had multiple anomalies. The researcher feels that this could be prevented if the mother would have been vaccinated before planning pregnancy as this is the only vaccine preventable condition. This view was supported by a study conducted by Dr. Ashlesha Kaushik, Department of Pediatrics, Division of Pediatric Infectious Disease, University of Texas, USA which stated that CRS is one of the most devastating congenital infections and yet the only one which is vaccine preventable and is a public health challenge for clinicians and policymakers across the developing world including India. The clinical manifestations of CRS include growth retardation, cardiac defects, cataracts, and hearing impairment.

The World Health Organization (WHO) estimates that worldwide over 100,000 babies are born with CRS every year despite the availability of safe and inexpensive vaccines, thus highlighting the need for broader vaccination coverage programs. This article briefly reviews the importance of CRS, the proposed strategies for prevention by the WHO, and the "rubella initiative" that Government of India is launching in view of the recognition of CRS as a significant problem in India. ${ }^{8}$

Another case report by Singh et al published online in 2017 in BMJ case reports describes a case of a preterm female infant who tested positive for the rubella virus with the mother being tested negative in first trimester of pregnancy. ${ }^{1,2}$ The baby was born with low birth weight and, on examination, showed pallor and hepatosplenomegaly. She was detected to have an ostium secundum atrial septal defect (ASD) and a large patent ductus arteriosus (PDA) on echocardiography. On ophthalmic examination, she was diagnosed with bilateral cataract. She was treated with diuretics, and she underwent surgical correction for PDA. On following treatment the baby was clinically fine. With this they focused on prevention, vaccination and disease burden in India. ${ }^{9}$

The author assumes that CRS is preventable and most of the time mother is affected but asymptomatic. Hence rubella screening is to be considered seriously and should be included in the routine antenatal investigations which would help in preventing the birth of the affected newborns and thus the neonatal and infant mortality.

\section{CONCLUSION}

Hence the author would like to conclude that, though very rare, CRS caused by rubella infection for mother during pregnancy was found to have many consequences to the fetus. Hence it is very significant to rule out rubella infection for mother during pregnancy or recently before pregnancy as a part of routine antenatal checkup as many of them are asymptomatic. All women should be insisted about getting vaccination for rubella minimum 28 days before planning for conception and vaccination should be strictly abandoned for women who were already pregnant.

Funding: No funding sources

Conflict of interest: None declared

Ethical approval: Not required

\section{REFERENCES}

1. Lanzieri $\mathrm{T}$, Redd S, Abernathy E, Icenogle J. Available at: www.cdc.gov/vaccines/pubs/survmanual/chpt15-crs.html\#description. Accessed on: 05 October 2020.

2. Ezike E, Ang JY. Pediatric Rubella. Medscape. Available at: http://emedicine.medscape.com/ article/968523-overview\#a4. Accessed on: 05 October 2020.

3. Centers for Disease Control \& Prevention. Manual for the Surveillance of Vaccine - Preventable Disease. Available at: https://www.cdc.gov/vaccines/pubs /surv-manual/chpt15. Accessed on: 05 October 2020.

4. Boston's Children Hospital. Congenital Rubella Symptoms \& Causes. Available at: http://www.childrenshospital.org/conditions-andtreatments/conditions/c/congenital-rubella/symptoms -and-causes. Accessed on: 06 October 2020.

5. Tesini BL. Congenital Rubella. MSD Manual Professional Version. Available at: https://www.msdmanuals.com/ professional/ pediatrics/infections-in-neonates/ congenital-rubella. Accessed on: 06 October 2020. 
6. Congenital rubella syndrome. Available at: https://en.m.wikipedia.org/wiki/Congenital_rubella_s yndrome. Accessed on: 06 October 2020.

7. Dutta P. Pediatric Nursing. 4th ed. Jaypee Brothers Medical Publishers (P) ltd. New Delhi. 2018;41.

8. Kaushik A, Verma S, Kumar P. Congenital rubella syndrome: A brief review of public health perspectives. Indian J Public Health. 2018;62(1):52-4.
9. Singh A, Narula S, Kareem H, Devasia T. An infant with congenital rubella syndrome in developing India. BMJ Case Rep. 2017;bcr2017221665.

Cite this article as: Kanagadurga M. A case report on congenital rubella syndrome. Int J Reprod Contracept Obstet Gynecol 2021;10:761-4. 